\title{
Pathological Correlates of White Matter Hyperintensities on Magnetic Resonance Imaging
}

\author{
Yong Soo Shim ${ }^{a}$ Dong-Won Yang ${ }^{a}$ Catherine M. Roe ${ }^{b}$ Mary A. Coats ${ }^{b}$ \\ Tammie L. Benzinger $^{b}$ Chengjie Xiong ${ }^{b}$ James E. Galvin ${ }^{c-e}$ \\ Nigel J. Cairns ${ }^{b}$ John C. Morris ${ }^{b}$ \\ a Department of Neurology, The Catholic University of Korea College of Medicine, Seoul, \\ South Korea; ${ }^{b}$ Knight Alzheimer's Disease Research Center, Washington University School \\ of Medicine, St. Louis, Mo., and Departments of ${ }^{\mathrm{C}}$ Neurology, ${ }^{\mathrm{d}}$ Psychiatry and ePopulation \\ Health, New York University Langone Medical Center, New York, N.Y., USA
}

\section{Key Words}

Small-vessel disease $\cdot$ Dementia $\cdot$ Neuropathology $\cdot$ Leukoaraiosis

\begin{abstract}
Background/Aims: We investigated the histopathological correlates of white matter hyperintensities (WMHs) in participants with Alzheimer's disease (AD) or cerebrovascular disease, and in aged controls. Methods: We reviewed 57 participants who had neuropathology and in whom neuroimaging was done. In addition to AD pathology, cortical microinfarcts, lacunes, and cerebral hemorrhages were assessed. Small-vessel disease included arteriolosclerosis and cerebral amyloid angiopathy. Postmortem brain tissue corresponding to regions of WMHs was investigated in 14 participants. The variables included: demyelination of the deep and periventricular white matter (WM), atrophy of the ventricular ependyma, and thickness of blood vessels. Partial Spearman's rank test and linear regression analysis, adjusted for age at the clinical evaluation and the duration to death, were performed. Results: The severity of arteriosclerosis was correlated with the volume of periventricular hyperintensity (PVH) estimated by magnetic resonance imaging. Deep white matter hyperintensity (DWMH) volume was correlated with the presence of cortical microinfarcts and cerebral hemorrhages. The severity of the breakdown of the ventricular lining was correlated with PVHs, and DWMHs correlated with the severity of deep WM demyelination. The diameter of small blood vessels was not associated with WMHs. Conclusion: WMHs are consistent with small-vessel disease and increase the tissue water content. We found no association between WMHs and the thickness of small blood vessels.


Shim et al.: Pathological Correlates of White Matter Hyperintensities on Magnetic Resonance Imaging

\section{Introduction}

White matter hyperintensities (WMHs) appear as lesions of increased signal intensity on T2-weighted and fluid-attenuated inversion recovery (FLAIR) magnetic resonance imaging (MRI) sequences [1]. They are frequently observed in healthy older adults as well as patients with dementia, including those with Alzheimer's disease (AD). In healthy older adults, WMHs are mostly regarded as a normal aging phenomenon, but severe WMHs have been associated with loss of specific cognitive functions such as psychomotor speed [2], although the association is weak and inconsistent [3-5]. In patients with AD, some studies have indicated that WMHs have an additive effect on cognitive decline, whereas others could not confirm this association [6-8]. A possible explanation for the inconsistent and weak associations between WMHs and clinical symptoms is heterogeneity in the neuropathology $[9,10]$.

WMHs have been correlated with cerebrovascular risk factors including hypertension, diabetes mellitus, smoking, hyperlipidemia, and cardiovascular disease [11-13], and are generally considered to be of vascular origin. They have been associated with arterial disease including intimal hyperplasia, atherosclerosis, arteriosclerosis, and lipohyalinosis [14]. Arterioles penetrating from the pial surface arteries have limited collateral supply and may contribute to white matter (WM) ischemia [14]. When severe, these ischemic areas may become necrotic and cystic lesions resulting from complete infarcts. However, the etiology of most WMHs, which are nonnecrotic, is less clear. Underlying neuropathological findings including myelin pallor (axon loss), reduced oligodendroglia numbers, astrocytosis, and microvacuolation may suggest other mechanisms [15-19]. Candidates include focal loss of ependymal lining with demyelination and gliosis, allowing leakage of ventricular cerebrospinal fluid $[16,17]$, accumulation of interstitial fluid in the perivascular spaces [18], edema related to blood-brain barrier disruption [19], and inflammatory processes involving microglial cells $[20,21]$. Some studies have failed to find any correlation between WMHs and neuropathology $[22,23]$. The reasons for such disparate findings are unclear, but the difficulty in performing neuropathological studies of areas identified by imaging may have contributed to the variable data, together with variation in the selection criteria of cases and the selection of neuropathological variables.

To address these diverse findings, we investigated the histopathological correlates of WMHs in longitudinally assessed participants with well-defined advanced risk factors for cerebrovascular disease (CVD) and with dementia of the Alzheimer type (DAT), as well as in aged controls.

\section{Methods}

From December 1995 to November 2000, a total of 165 participants were enrolled in a longitudinal study at the Washington University School of Medicine [24] called the 'Cognitive Change in Cerebrovascular Disease' (1430653611A1) project, which included clinical assessments, brain MRI, and autopsies. The sample consisted of three cohorts: participants with advanced risk for CVD ( $n=65)$, participants with DAT ( $n=48)$, and healthy, cognitively normal volunteers $(n=52)$. Participants with advanced risk for CVD were recruited from subjects who had angiographic evidence of at least $50 \%$ stenosis of one or both common carotid or internal carotid arteries [carotid stenosis (CS)], who did not undergo carotid endarterectomy, and who were local, St. Louis metropolitan-area participants enrolled in the Systolic Hypertension in the Elderly Program (SHEP) [25] with isolated systolic hypertension (systolic blood pressure between 160 and $219 \mathrm{~mm} \mathrm{Hg}$; diastolic blood pressure $<90 \mathrm{~mm} \mathrm{Hg}$ ). Participants with DAT and healthy volunteers were also recruited from the Washington University Knight Alzheimer's Disease Research Center. The diagnostic criteria for DAT were comparable with those for 'probable AD' according to the National Institute of Neurological and Communicative Disorders and Stroke and the Alzheimer's Disease and Related Disorders Association (NINCDSADRDA) [26]. Experienced clinicians conducted semistructured interviews with each participant and with a 
Shim et al.: Pathological Correlates of White Matter Hyperintensities on Magnetic Resonance Imaging

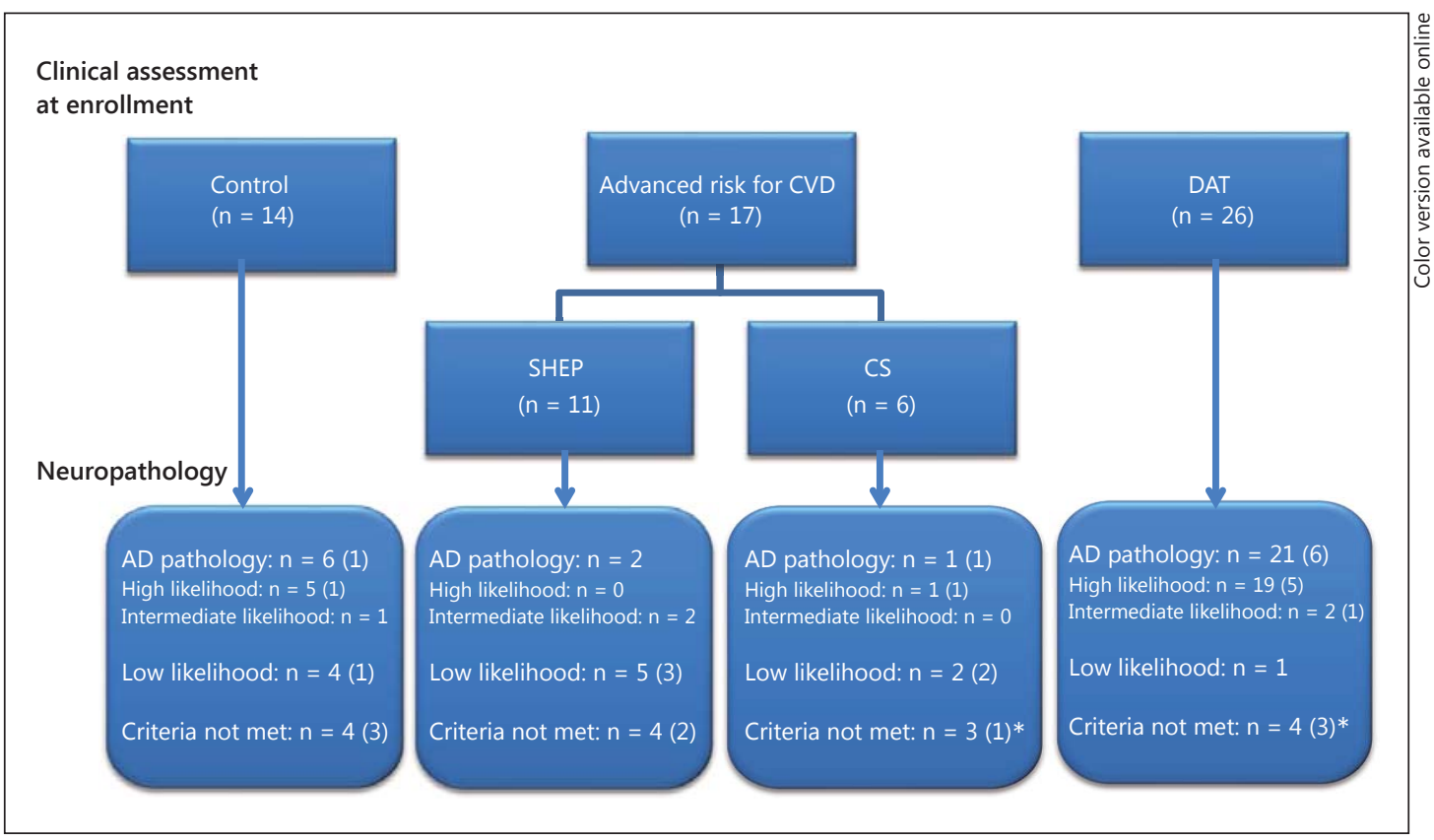

Fig. 1. Participants enrolled in the present study and their pathological findings. Numbers in parentheses represent cases at autopsy with pathologic features of CVD contributing to their cognitive status. * Among 23 subjects with pathologic evidence of CVD, vascular disease was considered primarily responsible for the cognitive status in 3 subjects ( 2 had $\mathrm{AD}$ and $1 \mathrm{CS}$ at clinical enrollment).

collateral source who was knowledgeable about the participant. A comprehensive health history was obtained from the collateral source and included the presence or history of hypertension, diabetes mellitus, stroke, or a transient ischemic attack. Trained registered nurses measured blood pressure at each annual visit using a manual cuff on the right or left arm. Exclusion criteria were the presence of any of the following: (1) other neurological disorders, including parkinsonism, Huntington's disease, communicating hydrocephalus, infection, brain tumor, subdural hematoma, multiple sclerosis, seizure disorder, and cerebral trauma; (2) psychiatric disorders, including major affective disorder, schizophrenia, and alcoholism or other substance abuse, and (3) reversible dementias and other medical disorders that may impair cognition, including overmedication, impaired pulmonary, cardiac, renal, or hepatic function, as well as anemia, hypothyroidism, vitamin $\mathrm{B}_{12}$ deficiency, malignancy, and insulin-dependent diabetes mellitus. Within 3 months of clinical assessment, brain MRI was performed using a 1.5-tesla image scanner (Siemens, Erlanger, Germany).

Both during and after the study, participants were followed up annually at the Knight Alzheimer's Disease Research Center. After death, brain autopsies were performed on 60 participants (18 with a CVD risk factor, 27 with DAT, and 15 healthy aged volunteers) as of December 2009. Of these 60 participants, FLAIR MRI was available for review from 57 participants (fig. 1).

Using the FLAIR images, a 3D-Slicer version 3.6 (3D-Slicer, Brigham and Women's Hospital, Inc., Boston, Mass., USA) was used to measure the volume of WMHs semiautomatically. WMHs were further distinguished by location into periventricular WMHs (PVHs), which were directly adjacent to the lateral ventricles, and deep WMHs (DWMHs), which were located in the subcortical WM. To correct for differences in head size, WMH volumes (including PVH and DWMH) were normalized by the total intracranial volume. For comparison, as a proxy for brain atrophy on FLAIR MRI, the ventricular volume, a global measure of the entire ventricular system, was also measured and classified as the ventricular index (VI).

Histology and immunohistochemistry were undertaken using a standard protocol [27]. Briefly, histological stains included hematoxylin and eosin, Luxol-fast blue/Nissl, and a modified Bielschowsky silver impregnation. Immunohistochemistry was performed using anti- $\beta$-amyloid (10D5), phosphorylated $\tau$ (PHF1), and $\alpha$-synuclein (LB509) antibodies. We used the Braak and Braak neurofibrillary tangle stage [28], and the presence of plaques was assessed according to the Consortium to Establish a Registry for Alzheimer's 


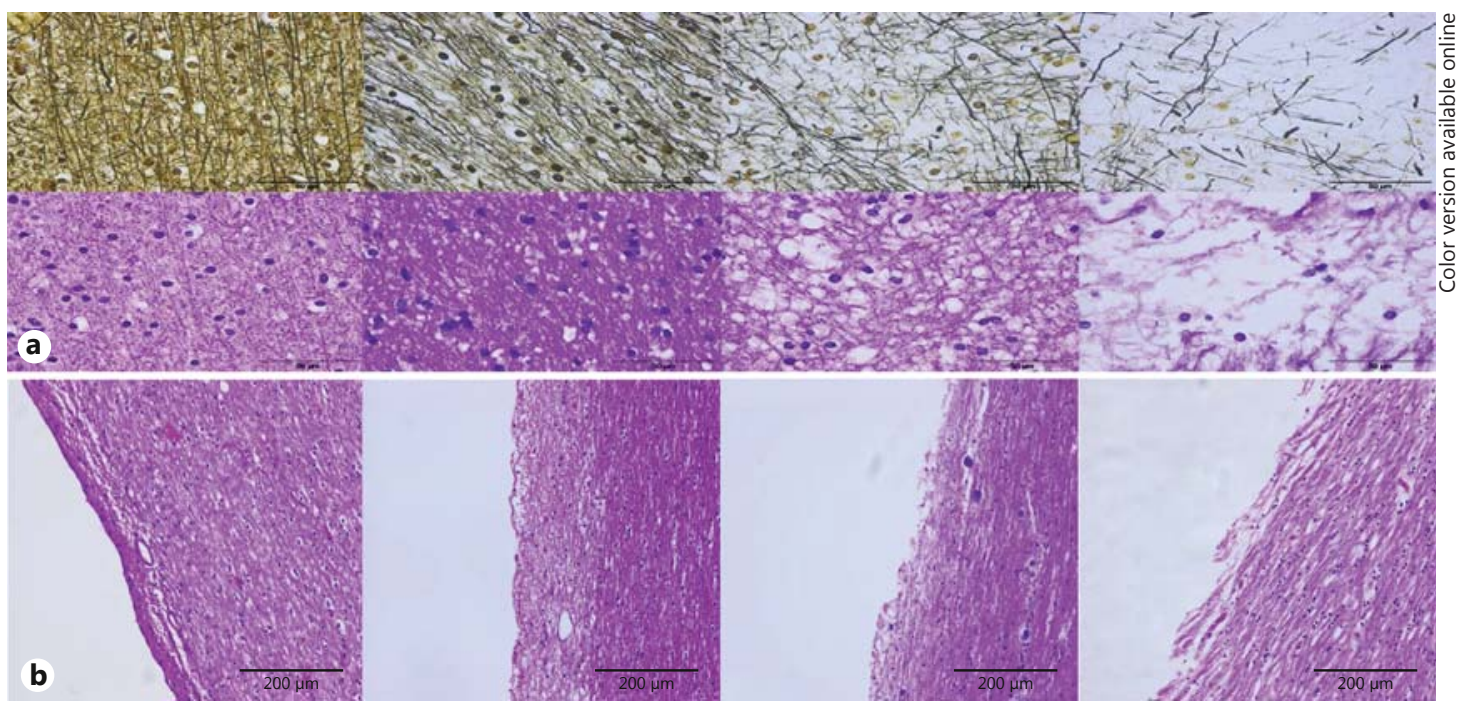

Fig. 2. Demonstration of visual rating scores for demyelination and atrophy of the ventricular ependyma. Tissue was assessed by: (1) estimating the percent loss of myelinated axons and (2) estimating the loss of ventricular ependyma; left to right: grade 0 (0-25\%) to grade 3 (75-100\%). a Demyelination. Modified Bielschowsky silver impregnation and HE. $\times 40$. b Atrophy of ventricular ependyma. HE. $\times 10$.

Disease (CERAD) guidelines [29]. The neuropathological diagnosis of AD was determined using the criteria of the National Institute on Aging and the Ronald Reagan Institute [30]. Vascular pathology was rated according to the criteria of the National Alzheimer's Coordinating Center [31] Neuropathology Manual version 9.1 (available at https://www.alz.washington.edu/WEB/forms-np.html). Large-vessel disease (atherosclerosis of the arteries of the circle of Willis, and of basilar, vertebral, and carotid arteries) and smallvessel disease [arteriolosclerosis and cerebral amyloid angiopathy (CAA)] were each rated on a 4-point scale (0-3). Additionally, the presence of large-artery cerebral infarcts, cortical microinfarcts, lacunes, cerebral hemorrhages, and subcortical arteriosclerotic leukoencephalopathy [32, 33] was recorded.

In addition, we studied areas of tissue corresponding to WMH regions in 14 participants. The severity of their WMHs was relevant to DWMHs scored $\geq 2$ or PVHs scored 3 according to the Fazekas visual rating scale [34]. Microscopic features included demyelination of the deep and periventricular WM, atrophy of the ventricular ependyma, and the number and diameter of the blood vessels in the WM. Demyelination of the WM was scored subjectively, ranging from normal to severe demyelination (scale: 0-3). Atrophy of the ventricular ependyma was assessed semiquantitatively (scale: 0-3) (fig. 2). The number of blood vessels was categorized as $1(<10), 2(11-20)$ or $3(>20$ per $\times 10$ microscope field).

Data analysis was performed using SPSS version 15.0 for Windows (SPSS, Inc., Chicago, Ill., USA). Subject demographics, neuropathology, and quantitative MRI measurements were compared between the three groups using the Kruskal-Wallis test and Fisher's exact test where appropriate. Quantitative MRI measurements were also compared using the Mann-Whitney U test between groups with and without the presence of specific pathological features. The relationships between clinical characteristics including MRI data and neuropathological measures were assessed using partial Spearman's rank test and linear regression analysis. All analyses were adjusted for age at clinical evaluation as well as duration to death. A p value $<0.05$ was considered significant.

\section{Results}

\section{Demographic Data}

Data from 57 participants (31 males and 26 females) were reviewed in this study. At clinical evaluation, there were 14 controls, 17 were at advanced risk for CVD (11 SHEP and 6 
Shim et al.: Pathological Correlates of White Matter Hyperintensities on Magnetic Resonance Imaging

Table 1. Clinical characteristics and MRI findings of participants

\begin{tabular}{|c|c|c|c|c|c|c|}
\hline & \multirow{2}{*}{$\begin{array}{l}\text { Control } \\
(n=14)\end{array}$} & \multicolumn{3}{|c|}{ Advanced risk for CVD } & \multirow{2}{*}{$\begin{array}{l}\text { DAT } \\
(n=26)\end{array}$} & \multirow{2}{*}{$\begin{array}{l}\mathrm{p} \\
\text { value }^{1}\end{array}$} \\
\hline & & total $(\mathrm{n}=17)$ & $\operatorname{SHEP}(n=11)$ & $\operatorname{CS}(n=6)$ & & \\
\hline \multicolumn{2}{|l|}{ Age upon clinical evaluation, } & $80.35 \pm 8.93$ & $84.73 \pm 3.29$ & $72.33 \pm 10.69$ & $74.88 \pm 9.18$ & $<0.001$ \\
\hline Age at autopsy, years & $90.93 \pm 5.95$ & $86.47 \pm 8.94$ & $90.82 \pm 5.47$ & $78.50 \pm 8.83$ & $80.65 \pm 9.15$ & $<0.001$ \\
\hline Duration to autopsy, years & $6.79 \pm 2.52$ & $6.12 \pm 4.09$ & $6.09 \pm 4.04$ & $6.17 \pm 4.58$ & $5.77 \pm 3.06$ & 0.694 \\
\hline Gender (M:F) & $5: 9$ & $10: 7$ & $6: 5$ & $4: 2$ & $16: 10$ & 0.421 \\
\hline Hypertension history & $6(42.86)$ & $15(88.24)$ & $11(100.00)$ & $4(66.67)$ & $6(23.08)$ & $<0.001$ \\
\hline DM history & $2(14.29)$ & $2(11.76)$ & $2(18.18)$ & $0(0.00)$ & $1(3.85)$ & 0.383 \\
\hline HIS & $0.64 \pm 0.93(0-3)$ & $3.53 \pm 3.54(0-10)$ & $1.91 \pm 2.70(0-9)$ & $6.50 \pm 3.02(2-10)$ & $0.50 \pm 1.07(0-5)$ & $<0.001$ \\
\hline CDR-SB & $0.07 \pm 0.18(0-0.5)$ & $1.26 \pm 2.50(0-9)$ & $1.14 \pm 2.66(0-9)$ & $1.50 \pm 2.41(0-6)$ & $5.15 \pm 2.92(0.5-11)$ & $<0.001$ \\
\hline \multicolumn{7}{|l|}{ MRI volume findings, $\mathrm{mm}^{3}$} \\
\hline WMHs & $9.39 \pm 10.56$ & $13.66 \pm 14.49$ & $10.08 \pm 7.32$ & $20.20 \pm 22.03$ & $8.21 \pm 10.68$ & 0.329 \\
\hline PVHs & $8.30 \pm 8.74$ & $11.67 \pm 13.25$ & $8.43 \pm 5.63$ & $17.60 \pm 20.81$ & $7.48 \pm 9.58$ & 0.465 \\
\hline DWMHs & $1.09 \pm 2.09$ & $1.99 \pm 1.90$ & $1.66 \pm 1.84$ & $2.60 \pm 2.03$ & $0.73 \pm 2.71$ & 0.304 \\
\hline
\end{tabular}

Values are presented as means \pm SD with ranges in parentheses or as numbers with percentages in parentheses. Age upon clinical evaluation and duration to death were adjusted for in the analyses. TICV = Total intracranial volume.

${ }^{1}$ Comparisons between the groups at clinical enrollment by using the Kruskal-Wallis test and Fisher's exact test, where appropriate.

CS), and 26 had DAT. At the last visit with available FLAIR MRI, the mean age \pm SD of the clinical enrollment groups was different $(p<0.001): 84.14 \pm 5.99$ years for the control group, $80.35 \pm 8.93$ years for the advanced risk for CVD group, $84.73 \pm 3.29$ years for the SHEP group, $72.33 \pm 10.69$ years for the CS group, and $74.88 \pm 9.18$ years for the DAT group. The duration from clinical evaluation to autopsy was $6.12 \pm 3.26$ years, and this did not differ between the clinical groups. After adjusting for age, the clinical dementia rating-sum of boxes (CDR-SB), the Hachinski ischemic scale (HIS), and history of hypertension were different between the groups $(\mathrm{p}<0.001)$. Other characteristics including gender, years of education, and diabetes history were not significantly different between the groups. MRI parameters of WMHs (including PVHs and DWMHs) and the VI were not significantly different across the three groups (table 1).

The volume of WMH, PVH, and DWMH and the VI increased with the advancing age of the participants. The age of the participants correlated with WMHs ( $r=0.36, p=0.005)$, PVHs $(r=0.38, p=0.004)$, DWMHs $(r=0.25, p=0.058)$, and the VI $(r=0.32, p=0.014)$. After adjusting for variables, the volumes of WMH and the VI were not significantly different across the three groups and were not associated with sex, years of education, CDR-SB, HIS, or the presence of hypertension or diabetes mellitus.

We further divided the participants into three groups according to their pathological findings. Participants who met the 'high likelihood' and 'intermediate likelihood' criteria of DAT according to the National Institute on Aging/Ronald Reagan Institute were designated as having 'AD pathology' $(\mathrm{n}=30)$. The remainder were subclassified into the groups 'low likelihood' $(\mathrm{n}=12)$ and 'criteria not met' $(\mathrm{n}=15)$. After adjusting for age and the duration to death, the HIS score ('AD pathology': $0.47 \pm 0.78$, range 0-3; 'low likelihood': $2.25 \pm 3.22$, range $0-8$; 'criteria not met': $2.73 \pm 3.31$, range $0-10 ; p=0.001$ ) and the history of hypertension ('AD pathology': $n=8,26.67 \%$; 'low likelihood': $n=9,75.00 \%$; 'criteria not met': $n=$ $10,66.67 \% ; p=0.008$ ) at the clinical evaluation were different between the three groups, and the presence of cortical microinfarcts ('AD pathology': $n=3,10.00 \%$; 'low likelihood': $n=3$, $25.00 \%$; 'criteria not met': $n=9,60.00 \% ; p=0.002$ ) was also different at autopsy. The number of participants with cortical microinfarcts at autopsy was distributed as follows: controls, $\mathrm{n}=5 ; \mathrm{CS}, \mathrm{n}=3$; SHEP, $\mathrm{n}=2 ; \mathrm{AD}, \mathrm{n}=5$ at clinical enrollment. The volume of WMH was $6.64 \pm$ 
Shim et al.: Pathological Correlates of White Matter Hyperintensities on Magnetic Resonance Imaging

Table 2. Findings of ischemic, hemorrhagic, and vascular pathology, according to the groups at the clinical enrollment (n)

\begin{tabular}{|c|c|c|c|c|c|c|}
\hline & \multirow{2}{*}{$\begin{array}{l}\text { Control } \\
(n=14)\end{array}$} & \multicolumn{3}{|c|}{ CVD risk $(n=17)$} & \multirow{2}{*}{$\begin{array}{l}\text { DAT } \\
(n=26)\end{array}$} & \multirow{2}{*}{$\begin{array}{l}\mathrm{p} \\
\text { value }^{1}\end{array}$} \\
\hline & & total & SHEP $(n=11)$ & $\operatorname{CS}(n=6)$ & & \\
\hline \multicolumn{7}{|l|}{ Vascular pathology } \\
\hline Large-artery cerebral infarcts & $1(7.14 \%)$ & $3(17.65 \%)$ & $1(9.09 \%)$ & $2(33.33 \%)$ & $2(7.69 \%)$ & 0.544 \\
\hline Cortical microinfarcts & $5(35.71 \%)$ & $5(29.41 \%)$ & $2(18.18 \%)$ & $3(50.00 \%)$ & $5(19.23 \%)$ & 0.550 \\
\hline Lacunes & $5(35.71 \%)$ & $6(35.29 \%)$ & $3(27.27 \%)$ & $3(50.00 \%)$ & $8(30.77 \%)$ & 0.933 \\
\hline Cerebral hemorrhages & $1(7.14 \%)$ & $2(11.76 \%)$ & $1(9.09 \%)$ & $1(16.67 \%)$ & $5(19.23 \%)$ & 0.627 \\
\hline \multicolumn{7}{|l|}{ Subcortical arteriosclerotic } \\
\hline leukoencephalopathy & $0(0.00 \%)$ & $1(5.88 \%)$ & $0(0.00 \%)$ & $1(16.67 \%)$ & $1(3.85 \%)$ & 0.675 \\
\hline Atherosclerosis (of the circle of Willis) & $14(100.00 \%)$ & $16(94.12 \%)$ & $10(90.91 \%)$ & $6(100.00 \%)$ & $22(84.62 \%)$ & 0.307 \\
\hline Arteriosclerosis & $14(100.00 \%)$ & $17(100.00 \%)$ & $11(100.00 \%)$ & $6(100.00 \%)$ & $25(96.15 \%)$ & 0.551 \\
\hline CAA & $11(78.57 \%)$ & $9(52.94 \%)$ & $7(63.64 \%)$ & $2(33.33 \%)$ & $22(84.62 \%)$ & 0.071 \\
\hline AD pathology & $6(42.867 \%)$ & $3(17.65 \%)$ & $2(18.18 \%)$ & $1(16.67 \%)$ & $21(80.77 \%)$ & \\
\hline
\end{tabular}

Age upon clinical evaluation and duration to death were adjusted for in the analyses.

${ }^{1}$ Comparisons between the groups at clinical enrollment by using Fisher's exact test.

$7.20 \mathrm{~mm}^{3}$ in those participants with AD pathology, $9.36 \pm 11.35 \mathrm{~mm}^{3}$ in the 'low likelihood' group, and $16.80 \pm 16.23 \mathrm{~mm}^{3}$ in the 'criteria not met' group ( $\left.\mathrm{p}=0.06\right)$.

The neuropathology of the 57 participants enrolled in this study and their pathology are shown in figure 1 . There were 23 participants with CVD ( 5 controls, 5 SHEP, 4 with CS, and 9 with DAT). Of these 23 participants, vascular disease was considered as the primary etiology of cognitive impairment in only 3 participants.

\section{Neuropathology of WMHS}

All 57 participants showed pathological evidence of vasculopathy. Arteriosclerosis of small parenchymal or leptomeningeal vessels was the most common finding $(n=56,98.25 \%)$, followed by atherosclerosis $(n=52,91.23 \%)$, CAA $(n=42,73.68 \%)$, lacunes $(n=19,33.33 \%)$, cortical microinfarcts $(n=15,26.32 \%)$, cerebral hemorrhages $(n=8,14.04 \%)$, large-artery cerebral infarcts $(n=6,10.63 \%)$, and subcortical arteriosclerotic leukoencephalopathy $(n=$ $2,3.51 \%$ ). These vascular pathologies were not different across the three groups according to the clinical presentation at enrollment. The presence of CAA was more frequent in participants with DAT $(n=22,84.62 \%)$, although this did not reach significance $(\mathrm{p}=0.071)$ (table 2$)$. The distribution of vascular pathologies was not different between the 14 participants with WMHs and those without.

After adjusting for age and duration to death, the Braak and Braak neurofibrillary tangle stage was inversely correlated with the volume of WMH $(r=-0.268, p=0.023)$ and PVH $(r=$ $-0.276, p=0.020$ ). The burden of neuritic and diffuse plaques, according to the CERAD stages, showed a borderline association with WMH ( $r=-0.180, \mathrm{p}=0.092$, and $\mathrm{r}=-0.175, \mathrm{p}=0.098)$. As the volume of DWMH increased, the score of diffuse plaques ( $r=-0.234, p=0.041)$, and to some extent the score of neuritic plaques ( $r=-0.177, \mathrm{p}=0.096)$, decreased. In the linear regression analysis, the neurofibrillary tangle stage was associated with WMHs ( $p=0.026)$ and PVHs ( $\mathrm{p}=0.022)$ (table 3).

DWMH volume was correlated with cortical microinfarcts $(\mathrm{r}=0.259, \mathrm{p}=0.027)$ and cerebral hemorrhages $(\mathrm{r}=0.344, \mathrm{p}=0.004)$. It was $0.84 \pm 1.61 \mathrm{~mm}^{3}$ (total intracranial volume $\left.1,469.98 \pm 162.45 \mathrm{~mm}^{3}\right)$ in participants without cortical microinfarct $(\mathrm{n}=42)$ and $2.19 \pm 3.65$ $\mathrm{mm}^{3}$ (total intracranial volume $1,459.53 \pm 115.37 \mathrm{~mm}^{3}$ ) in those with cortical microinfarcts 
Dementia

Cognitive Disorders

\begin{tabular}{l|l}
\hline \multicolumn{2}{l}{ Dement Geriatr Cogn Disord 2015;39:92-104 } \\
\hline DOI: 10.1159/000366411 & $\begin{array}{l}\text { C 2014 S. Karger AG, Basel } \\
\text { www.karger.com/dem }\end{array}$ \\
\hline
\end{tabular}

Shim et al.: Pathological Correlates of White Matter Hyperintensities on Magnetic Resonance Imaging

Table 3. Linear regression models evaluating the association between neuropathological variables and MRI parameters

\begin{tabular}{llcrrr}
\hline Dependent variables & Independent variables & Regression coefficient & Constant & $\mathrm{R}^{2}$ & $\mathrm{p}$ value \\
\hline WMHs & Neurofibrillary tangles & -0.001 & 0.012 & 0.070 & 0.026 \\
& Breakdown of ventricular lining & 0.006 & 0.004 & 0.263 & 0.035 \\
PVHs & Neurofibrillary tangles & -0.001 & 0.011 & 0.075 & 0.022 \\
& Breakdown of ventricular lining & 0.005 & 0.004 & 0.234 & 0.046 \\
DWMHs & Arteriosclerosis & 0.002 & -0.001 & 0.078 & 0.020 \\
& Microinfarcts & 0.001 & 0.001 & 0.054 & 0.045 \\
& Cerebral hemorrhages & 0.002 & 0.001 & 0.095 & 0.011 \\
\hline
\end{tabular}

Adjusted for age at clinical evaluation and duration to death.

( $\mathrm{n}=15 ; \mathrm{p}=0.038$ ), and $0.90 \pm 1.65 \mathrm{~mm}^{3}$ (total intracranial volume 1,477.19 $\pm 136.94 \mathrm{~mm}^{3}$ ) in participants without cerebral hemorrhage $(\mathrm{n}=49)$ and $3.02 \pm 4.65 \mathrm{~mm}^{3}$ (total intracranial volume $\left.1,406.25 \pm 218.68 \mathrm{~mm}^{3}\right)$ in those with cerebral hemorrhages $(\mathrm{n}=8 ; \mathrm{p}=0.005)$. The severity of arteriosclerosis was correlated with the volume of PVH $(r=0.260, p=0.027)$ and WMH ( $\mathrm{r}=0.213, \mathrm{p}=0.058)$.

In the linear regression analysis, DWMH was associated with microinfarcts $(p=0.045)$ and cerebral hemorrhages $(p=0.011)$. PVH was associated with arteriosclerosis $(p=0.02)$ (table 3).

\section{Further Evaluation}

For further evaluation of the change in small-vessel disease, we reviewed the microscopic examination of tissues corresponding to the WMH regions in 14 participants who had at least some WMHs. The severity of the breakdown of the ventricular lining was correlated with the volume of the WMH and PVH (all: $r=0.559, p=0.019$ ), and the volume of DWMH was correlated with deep WM demyelination $(r=0.571, p=0.016)$. Decreased vessel density was observed in the periventricular WM in particular. The number of vessels in the periventricular WM was correlated with the volume of WMH $(r=-0.400, p=0.078)$ and PVH $(r=$ $-0.401, p=0.078)$. The VI was correlated with deep WM demyelination $(r=-0.509, p=0.032)$. The thickness of blood vessels was not correlated with WMHs.

In the regression analysis, the loss of ventricular lining was related to WMHs ( $\mathrm{p}=0.035)$ and PVHs $(\mathrm{p}=0.046)$, and deep WM demyelination was related to DWMHs $(\mathrm{p}=0.007)$ (table 3).

\section{Discussion}

The present study examined the pathological correlates of WMHs in patients with DAT and in cognitively normal older adults. We quantitatively measured the volume of WMHs (especially PVHs and DWMHs) separately and as a total amount of WMHs. Furthermore, we investigated areas of tissue corresponding to WMH regions in subjects with at least some WMHs. We found that DWMHs are associated with deep WM demyelination, and the breakdown of the ventricular lining was associated with PVHs and WMHs. In the sample comprising all participants, WMHs inversely correlated with neurofibrillary tangles, supporting the concept of synergistic pathologies. Interestingly, neurofibrillary tangles were associated with the volume of $\mathrm{PVH}$, and diffuse plaques were associated with the volume of 
DWMH, indicating that AD pathology may contribute to the vascular or WM pathology. The reasons for these findings are difficult to explain and require further investigation. Our results are, however, similar to previously reported patterns of severe comorbid cerebrovascular lesions in $\mathrm{AD}$ patients $[35,36]$. In line with these results, our findings could be interpreted to indicate that cerebrovascular lesions lower the threshold for developing clinical symptoms. As the pathological burden of small-vessel disease such as arteriosclerosis increased, the volume of PVH also increased, and there was a correlation between DWMHs and cortical microinfarcts and cerebral hemorrhages.

Previous studies indicate that WMHs may reflect partial loss of myelin and axons, astrogliosis, dilatation of perivascular spaces, and fibrohyalinotic vessel changes [22, 37-39]. This range of tissue changes was thought to reflect incomplete infarction; also, complete infarcts were found to be associated with WMHs with arteriolosclerotic vessel changes in some studies $[37,39,40]$. Regarding the pathogenetic mechanisms underlying WMHs, the role of hypoxia is supported in a number of studies [41-43]. Human cerebral WM is particularly vulnerable to hypoperfusion due to the impaired perfusion and reduced cerebral blood flow through the terminal long penetrating arterioles $[14,44]$. These arteries do not anastomose or form collaterals. The altered blood flow, thereby, results in a watershed phenomenon within the deep WM. The compensated chronic ischemia may turn into acute hypoxia due to reduced blood pressure. These changes lead to focal neuronal atrophy and the loss of myelin [43]. The resultant hypoxia may not be severe enough to cause cerebral necrosis or damage to the gray matter, but it is sufficient to result in WM changes. Other studies showed arteriolar tortuosity and decreased vessel densities in WMHs $[45,46]$, which also supports an ischemic pathogenesis of WMHs.

In the present study, WMHs were associated with demyelination, loss of ependymal cells, arteriosclerosis, microinfarcts, and cerebral hemorrhages, although not all cases exhibited these characteristics. Loss of myelinated axons and breakdown of the ventricular lining were correlated with DMWHs and PVHs, respectively, as has been demonstrated by previous studies $[16,38,47]$. Breakdown of the ventricular lining and loss of myelinated axons may cause leakage of cerebrospinal fluid into the WM, leading to WM pallor and higher signal intensity due to ventricular widening and WM atrophy, which could be caused by subcortical 'incomplete infarcts' [48]. However, the term 'incomplete infarcts' is controversial and not clearly defined, although it was suggested as being characteristic of leukoaraiosis [49]. Moreover, other studies have proposed that these pathological findings provide evidence of alternate mechanisms to ischemia because they involve no direct vascular changes $[15,50$, 51]. Although we could not directly observe the correlation with vessel thickness, PVHs showed a correlation with arteriolosclerosis, as has been shown in previous studies [39, 47], which could cause hypoperfusion of the WM and somewhat reduced vessel densities. Microinfarcts and cerebral hemorrhages, which correlated with DWMHs in this study, may also be caused by small-vessel disease. In contrast to previous studies [42, 43], we could not find any association with vessel thickness. Previous studies classified only severe cases (a Wahlund scale score of 2.5-3 [52]) as leukoaraiosis, but our study included only mild WMHs compared to those two studies.

In clinical studies using MRI, an attempt to improve the specificity for WMHs was made by distinguishing between PVHs and DWMHs [34], and histopathology has demonstrated that each type of WMH reflects a distinct pathological change [19, 47, 53-55]. Van Swieten et al. [39] suggested that arteriolosclerosis was the primary causative factor for DWMHs in cognitively normal older adults with cerebrovascular risk factors. PVHs are often considered to be related to normal aging $[16,56]$, representing the demyelination associated with subependymal gliosis and discontinuity of the ependymal lining [47]. Our study revealed an association between PVHs and neurofibrillary tangle stages and DWMHs with diffuse plaques. The 
Shim et al.: Pathological Correlates of White Matter Hyperintensities on Magnetic Resonance Imaging

volume of WMH including PVH and DWMH increased with advancing age, and PVHs were associated with loss of ventricular lining. DWMHs were associated with deep WM demyelination. However, microinfarcts and cerebral hemorrhages in DWMHs and arteriosclerosis in PVHs are the likely consequences of small-vessel disease [38, 57-59]; thus, our findings of loss of myelin and ventricular lining might also be considered to result from ischemia or small-vessel disease $[38,56]$. Previous studies have suggested that mild forms of WMH may not be clinically relevant or even detectable [60], but irregular PVHs and confluent DWMHs correspond to more severe tissue changes, probably of ischemic origin, and are more likely to produce clinical symptoms $[40,47,54,60]$. The variability in the data may reflect the heterogeneity in the different cohorts studied. For example, in the relatively healthy NUN study cohort, evidence of ischemia was not found in severe DWMHs [61]. Moreover, the significance of WMHs will be different according to the clinical stage of the disease. Individuals with early-stage AD may be more vulnerable to the cognitive effect of WMHs than cognitively normal older adults with a similar WMH burden [62]. WMHs have been related to the different etiologies according to severity [63], and WMHs on MRI could be used in addition to complement neuropathological postmortem assessment of subcortical vascular pathology of the WM [64].

The present study has some limitations. First, cerebrovascular risk factors did not correlate significantly with the volume of WMH after adjusting for age, although subjects with advanced risk factors generally displayed higher volumes of WMH. Also, we could not find any associations between WMHs and clinical or pathological variables. This may be due to the small sample size. With a larger sample size, further evaluation classifying the subjects' cognitive and pathological findings as well as cerebrovascular risk factors could provide more conclusive results. It should be mentioned that the relationship between cerebrovascular lesions and $\mathrm{AD}$ pathologies is still controversial, with some studies indicating positive associations [65-68], others indicating negative associations [35, 36, 69], and still others failing to detect any associations $[70,71]$. However, the inverse relationship between WMHs and neurofibrillary tangles in this study may support a synergy between WM pathology and AD. In this study, we did not measure the number of lacunes in contrast to a previous study [59]. Although we did not find an association between WMHs and lacunes, we observed that many cases (33.33\%) had lacunes which were associated with small-vessel disease [38, 57-59]. Lastly, and most importantly, our study does not necessarily prove whether WMHs develop as a result of ischemia or whether they are the consequence of impaired cell metabolism secondary to many other possible processes. Disrupted ependymal lining of the ventricles could result from cerebral atrophy and ventricular dilatation, which may be the consequence of neurodegenerative processes rather than small-vessel disease [51]. Other proposed mechanisms include blood-brain barrier dysfunction [34, 40, 44, 46, 72, 73], inflammatory processes involving microglial cells $[20,21,74]$, altered cerebral blood flow autoregulation, axonal depletion from Wallerian degeneration [75], and intraparenchymal venular disease $[76,77]$. All of these potential causes warrant further investigation $[14,49]$.

Our data indicate that WMHs increase with age, and we can suggest cautiously that WMHs might progress from periventricular WM to deep WM. PVHs increase with arteriosclerosis and DWMHs increase with microinfarcts and cerebral hemorrhages. WMHs correlated with WM pathology including breakdown of the ventricular lining and deep WM demyelination. These observations are suggestive of a potential increase in water content and, possibly, a consequence of small-vessel disease, although we could find no association between WMHs and the thickness of small vessels. 
Shim et al.: Pathological Correlates of White Matter Hyperintensities on Magnetic Resonance Imaging

\section{Acknowledgments}

This study was supported in part by a grant (No. HI10C2020) from the Korea Healthcare Technology R\&D Project, Ministry of Health and Welfare, Republic of Korea, by National Institute on Aging Grants P50AG005681 and P01AG003991, and the Charles F. and Joanne Knight Alzheimer's Initiative. We thank the staff of the Neuropathology Core of the Knight Alzheimer's Disease Research Center for their histological expertise and assistance.

\section{Disclosure Statement}

We have no conflicts of interest to declare.

\section{References}

1 Murray AD, Staff RT, Shenkin SD, Deary IJ, Starr JM, Whalley LJ: Brain white matter hyperintensities: relative importance of vascular risk factors in nondemented elderly people. Radiology 2005;237:251-257.

-2 de Groot JC, de Leeuw FE, Oudkerk M, van Gijn J, Hofman A, Jolles J, Breteler MM: Cerebral white matter lesions and cognitive function: the Rotterdam Scan Study. Ann Neurol 2000;47:145-151.

-3 O'Brien JT, Wiseman R, Burton EJ, Barber B, Wesnes K, Saxby B, Ford GA: Cognitive associations of subcortical white matter lesions in older people. Ann NY Acad Sci 2002;977:436-444.

-4 Schmidt R, Ropele S, Enzinger C, Petrovic K, Smith S, Schmidt H, Matthews PM, Fazekas F: White matter lesion progression, brain atrophy, and cognitive decline: the Austrian stroke prevention study. Ann Neurol 2005;58: 610-616.

-5 van der Flier WM, van Straaten EC, Barkhof F, Verdelho A, Madureira S, Pantoni L, Inzitari D, Erkinjuntti T, Crisby M, Waldemar G, Schmidt R, Fazekas F, Scheltens P: Small vessel disease and general cognitive function in nondisabled elderly: the LADIS study. Stroke 2005;36:2116-2120.

6 Stout JC, Jernigan TL, Archibald SL, Salmon DP: Association of dementia severity with cortical gray matter and abnormal white matter volumes in dementia of the Alzheimer type. Arch Neurol 1996;53:742-749.

7 Hirono N, Kitagaki H, Kazui H, Hashimoto M, Mori E: Impact of white matter changes on clinical manifestation of Alzheimer's disease: a quantitative study. Stroke 2000;31:2182-2188.

8 Mungas D, Jagust WJ, Reed BR, Kramer JH, Weiner MW, Schuff N, Norman D, Mack WJ, Willis L, Chui HC: MRI predictors of cognition in subcortical ischemic vascular disease and Alzheimer's disease. Neurology 2001;57: $2229-2235$.

-9 Scheltens P, Barkhof F, Valk J, Algra PR, van der Hoop RG, Nauta J, Wolters EC: White matter lesions on magnetic resonance imaging in clinically diagnosed Alzheimer's disease. Evidence for heterogeneity. Brain 1992;115: 735-748.

10 Schmidt R, Schmidt H, Haybaeck J, Loitfelder M, Weis S, Cavalieri M, Seiler S, Enzinger C, Ropele S, Erkinjuntti T, Pantoni L, Scheltens P, Fazekas F, Jellinger K: Heterogeneity in age-related white matter changes. Acta Neuropathol 2011;122:171-185.

11 Fazekas F, Niederkorn K, Schmidt R, Offenbacher H, Horner S, Bertha G, Lechner H: White matter abnormalities in normal individuals: correlation with carotid ultrasonography, cerebral blood flow measurements, and cerebrovascular risk factors. Stroke 1988;19:1285-1288.

12 Lazarus R, Prettyman R, Cherryman G: White matter lesions on magnetic resonance imaging and their relationship with vascular risk factors in memory clinic attenders. Int J Geriatr Psychiatry 2005;20:274-279.

-13 Lechner H, Schmidt R, Bertha G, Justich E, Offenbacher H, Schneider G: Nuclear magnetic resonance image white matter lesions and risk factors for stroke in normal individuals. Stroke 1988;19:263-265.

14 Pantoni L, Garcia JH: Pathogenesis of leukoaraiosis. Stroke 1997;28:652-659.

15 Simpson JE, Fernando MS, Clark L, Ince PG, Matthews F, Forster G, O’Brien JT, Barber R, Kalaria RN, Brayne C, Shaw PJ, Lewis CE, Wharton SB; MRC Cognitive Function and Ageing Neuropathology Study Group: White matter lesions in an unselected cohort of the elderly: astrocytic, microglial and oligodendrocyte precursor cell responses. Neuropathol Appl Neurobiol 2007;33:410-419.

16 Sze G, De Armond S, Brant-Zawadzki M, Davis RL, Norman D, Newton TH: Foci of MRI signal (pseudo lesions) anterior to the frontal horns: histologic correlations of a normal finding. AJR Am J Roentgenol 1986;147:331337.

17 Scheltens P, Barkhof F, Leys D, Wolters EC, Ravid R, Kamphorst W: Histopathologic correlates of white matter changes on MRI in Alzheimer's disease and normal aging. Neurology 1995;45:883-888.

18 Rennels ML, Blaumanis OR, Grady PA: Rapid solute transport throughout the brain via paravascular fluid pathways. Adv Neurol 1990;52:431- 439.

19 Munoz DG, Hastak SM, Harper B, Lee D, Hachinski VC: Pathologic correlates of increased signals of the centrum ovale on magnetic resonance imaging. Arch Neurol 1993;50:492-497. 
Shim et al.: Pathological Correlates of White Matter Hyperintensities on Magnetic Resonance Imaging

-20 Simpson JE, Ince PG, Higham CE, Gelsthorpe CH, Fernando MS, Matthews F, Forster G, O’Brien JT, Barber R, Kalaria RN, Brayne C, Shaw PJ, Stoeber K, Williams GH, Lewis CE, Wharton SB; MRC Cognitive Function and Ageing Neuropathology Study Group: Microglial activation in white matter lesions and nonlesional white matter of ageing brains. Neuropathol Appl Neurobiol 2007;33:670-683.

-21 Simpson JE, Fernando MS, Clark L, Ince PG, Matthews F, Forster G, O’Brien JT, Barber R, Kalaria RN, Brayne C, Shaw PJ, Lewis CE, Wharton SB; MRC Cognitive Function and Ageing Neuropathology Study Group: White matter lesions in an unselected cohort of the elderly: astrocytic, microglial and oligodendrocyte precursor cell responses. Neuropathol Appl Neurobiol 2007;33:410-419.

-22 Awad IA, Johnson PC, Spetzler RF, Hodak JA: Incidental subcortical lesions identified on magnetic resonance imaging in the elderly. II. Postmortem pathological correlations. Stroke 1986;17:1090-1097.

23 Braffman BH, Zimmerman RA, Trojanowski JQ, Gonatas NK, Hickey WF, Schlaepfer WW: Brain MR: pathologic correlation with gross and histopathology. 2. Hyperintense white-matter foci in the elderly. AJR Am J Roentgenol 1988;151:559-566.

-24 Berg L, McKeel DW Jr, Miller JP, Storandt M, Rubin EH, Morris JC, Baty J, Coats M, Norton J, Goate AM, Price JL, Gearing M, Mirra SS, Saunders AM: Clinicopathologic studies in cognitively healthy aging and Alzheimer's disease: relation of histologic markers to dementia severity, age, sex, and apolipoprotein E genotype. Arch Neurol 1998;55:326-335.

-25 Probstfield JL, Applegate WB, Borhani NO, Curb JD, Cutler JA, Davis BR, Furberg CD, Hawkins CM, Lakatos E, Page LB, Perry HM, Schron E, Smith WM: The Systolic Hypertension in the Elderly Program (SHEP): an intervention trial on isolated systolic hypertension. SHEP Cooperative Research Group. Clin Exp Hypertens A 1989; 11:973-989.

26 McKhann G, Drachman D, Folstein M, Katzman R, Price D, Stadlan EM: Clinical diagnosis of Alzheimer's disease: report of the NINCDS-ADRDA Work Group under the auspices of Department of Health and Human Services Task Force on Alzheimer's Disease. Neurology 1984;34:939-944.

-27 Price JL, McKeel DW Jr, Buckles VD, Roe CM, Xiong C, Grundman M, Hansen LA, Petersen RC, Parisi JE, Dickson DW, Smith CD, Davis DG, Schmitt FA, Markesbery WR, Kaye J, Kurlan R, Hulette C, Kurland BF, Higdon R, Kukull W, Morris JC: Neuropathology of nondemented aging: presumptive evidence for preclinical Alzheimer disease. Neurobiol Aging 2009;30:1026-1036.

28 Braak H, Braak E: Neuropathological stageing of Alzheimer-related changes. Acta Neuropathol 1991;82:239259.

29 Mirra SS, Hart MN, Terry RD: Making the diagnosis of Alzheimer's disease: a primer for practicing pathologists. Arch Pathol Lab Med 1993;117:132-144.

-30 Hyman BT, Trojanowski JQ: Consensus recommendations for the postmortem diagnosis of Alzheimer disease from the National Institute on Aging and the Reagan Institute Working Group on diagnostic criteria for the neuropathological assessment of Alzheimer disease. J Neuropathol Exp Neurol 1997;56:1095-1097.

-31 Beekly DL, Ramos EM, van Belle G, Deitrich W, Clark AD, Jacka ME, Kukull WA; NIA-Alzheimer's Disease Centers: The National Alzheimer's Coordinating Center (NACC) Database: an Alzheimer disease database. Alzheimer Dis Assoc Disord 2004;18:270-277.

32 Roman GC: Senile dementia of the Binswanger type. A vascular form of dementia in the elderly. JAMA 1987; 258:1782-1788.

33 Caplan LR: Binswanger's disease-revisited. Neurology 1995;45:626-633.

-34 Fazekas F, Chawluk JB, Alavi A, Hurtig HI, Zimmerman RA: MR signal abnormalities at 1.5 T in Alzheimer's dementia and normal aging. AJR Am J Roentgenol 1987;149:351-356.

-35 Goulding JM, Signorini DF, Chatterjee S, Nicoll JA, Stewart J, Morris R, Lammie GA: Inverse relation between Braak NFT stage and cerebrovascular pathology in Alzheimer predominant dementia. J Neurol Neurosurg Psychiatry 1999;67:654-657.

-36 Nagy Z, Esiri MM, Jobst KA, Morris JH, King EM, McDonald B, Joachim C, Litchfield S, Barnetson L, Smith AD: The effects of additional pathology on the cognitive deficit in Alzheimer disease. J Neuropathol Exp Neurol 1997;56:165-170.

-37 Englund E, Brun A, Persson B: Correlations between histopathologic white matter changes and proton MR relaxation times in dementia. Alzheimer Dis Assoc Disord 1987;1:156-170.

38 Révész T, Hawkins CP, du Boulay EP, Barnard RO, McDonald WI: Pathological findings correlated with magnetic resonance imaging in subcortical arteriosclerotic encephalopathy (Binswanger's disease). J Neurol Neurosurg Psychiatry 1989;52:1337-1344.

39 van Swieten JC, van den Hout JH, van Ketel BA, Hijdra A, Wokke JH, van Gijn J: Periventricular lesions in the white matter on magnetic resonance imaging in the elderly. A morphometric correlation with arteriolosclerosis and dilated perivascular spaces. Brain 1991;114:761-774.

40 Marshall VG, Bradley WG Jr, Marshall CE, Bhoopat T, Rhodes RH: Deep white matter infarction: correlation of MR imaging and histopathologic findings. Radiology 1988;167:517-522.

41 Fernando MS, Simpson JE, Matthews F, Brayne C, Lewis CE, Barber R, Kalaria RN, Forster G, Esteves F, Wharton SB, Shaw PJ, O’Brien JT, Ince PG; MRC Cognitive Function and Ageing Neuropathology Study Group: White matter lesions in an unselected cohort of the elderly: molecular pathology suggests origin from chronic hypoperfusion injury. Stroke 2006;37:1391-1398.

-42 Auriel E, Bornstein NM, Berenyi E, Varkonyi I, Gabor M, Majtenyi K, Szepesi R, Goldberg I, Lampe R, Csiba L: Clinical, radiological and pathological correlates of leukoaraiosis. Acta Neurol Scand 2011;123:41-47. 
Shim et al.: Pathological Correlates of White Matter Hyperintensities on Magnetic Resonance Imaging

43 Auriel E, Csiba L, Berenyi E, Varkonyi I, Mehes G, Kardos L, Karni A, Bornstein NM: Leukoaraiosis is associated with arterial wall thickness: a quantitative analysis. Neuropathology 2012;32:227-233.

44 Young VG, Halliday GM, Kril JJ: Neuropathologic correlates of white matter hyperintensities. Neurology 2008; 71:804-811.

45 Moody DM, Thore CR, Anstrom JA, Challa VR, Langefeld CD, Brown WR: Quantification of afferent vessels shows reduced brain vascular density in subjects with leukoaraiosis. Radiology 2004;233:883-890.

46 Brown WR, Moody DM, Challa VR, Thore CR, Anstrom JA: Venous collagenosis and arteriolar tortuosity in leukoaraiosis. J Neurol Sci 2002;203-204:159-163.

-47 Fazekas F, Kleinert R, Offenbacher H, Schmidt R, Kleinert G, Payer F, Radner H, Lechner H: Pathologic correlates of incidental MRI white matter signal hyperintensities. Neurology 1993;43:1683-1639.

-48 Brun A, Englund E: A white matter disorder in dementia of the Alzheimer type: a pathoanatomical study. Ann Neurol 1986;19:253-262.

49 Munoz DG: Leukoaraiosis and ischemia: beyond the myth. Stroke 2006;37:1348-1349.

50 Black S, Gao FQ, Bilbao J: Understanding white matter disease: imaging-pathological correlation in vascular cognitive impairment. Stroke 2009;40:S48-S52.

51 Morris JC, Gado M, Torack RM, McKeel DW Jr: Binswanger's disease or artifact: a clinical, neuroimaging, and pathological study of periventricular white matter changes in Alzheimer's disease. Adv Neurol 1990;51: 47-51.

52 Wahlund LO, Barkhof F, Fazekas F, Bronge L, Augustin M, Sjögren M, Wallin A, Ader H, Leys D, Pantoni L, Pasquier F, Erkinjuntti T, Scheltens P; European Task Force on Age-Related White Matter Changes: A new rating scale for age-related white matter changes applicable to MRI and CT. Stroke 2001;32:1318-1322.

-53 Fazekas F, Kleinert R, Offenbacher H, Payer F, Schmidt R, Kleinert G, Radner H, Lechner H: The morphologic correlate of incidental punctate white matter hyperintensities on MR images. AJNR Am J Neuroradiol 1991; 12:915-921.

54 Chimowitz MI, Estes ML, Furlan AJ, Awad IA: Further observations on the pathology of subcortical lesions identified on magnetic resonance imaging. Arch Neurol 1992;49:747-752.

55 Udaka F, Sawada H, Kameyama M: White matter lesions and dementia: MRI pathological correlation. Ann NY Acad Sci 2002; 977:411-415.

-56 Leifer D, Buonanno FS, Richardson EP Jr: Clinicopathologic correlations of cranial magnetic resonance imaging of periventricular white matter. Neurology 1990;40:911-918.

57 Rossi R, Joachim C, Geroldi C, Combrinck M, Esiri MM, Smith AD, Frisoni GB: Association between subcortical vascular disease on CT and neuropathological findings. Int J Geriatr Psychiatry 2004;19:690-695.

58 Gouw AA, Seewann A, van der Flier WM, Barkhof F, Rozemuller AM, Scheltens P, Geurts JJG: Heterogeneity of small vessel disease: a systematic review of MRI and histopathology correlations. J Neurol Neurosurg Psychiatry 2011;82:126-135.

59 Jagust WJ, Zheng L, Harvey DJ, Mack WJ, Vinters HV, Weiner MW, Ellis WG, Zarow C, Mungas D, Reed BR, Kramer JH, Schuff N, DeCarli C, Chui HC: Neuropathological basis of magnetic resonance images in aging and dementia. Ann Neurol 2008;63:72-80.

60 Scarpelli M, Salvolini U, Diamanti L, Montironi R, Chiaromoni L, Maricotti M: MRI and pathological examination of post-mortem brains: the problem of white matter high signal areas. Neuroradiology 1994;36:393-398.

-61 Smith CD, Snowdon D, Markesbery WR: Periventricular white matter hyperintensities on MRI: correlation with neuropathologic findings. J Neuroimaging 2000;10:13-16.

62 Burns JM, Church JA, Johnson DK, Xiong CX, Marcus D, Fotenos AF, Snyder AZ, Morris JC, Buckner RL: White matter lesions are prevalent but differently related with cognition an aging and early Alzheimer disease. Arch Neurol 2005;62:1870-1876.

63 Fazekas F, Kleinert R, Offenbacher H, Schmidt R, Kleinert G, Payer F, Radner H, Lechner H: Pathologic correlates of incidental MRI white matter signal hyperintensities. Neurology 1993;43:1683-1689.

64 McAleese KE, Firbank M, Hunter D, Sun L, Hall R, Neal JW, Mann DM, Esiri M, Jellinger KA, O’Brien JT, Attems J: Magnetic resonance imaging of fixed post mortem brains reliably reflects subcortical vascular pathology of frontal, parietal and occipital white matter. Neuropathol Appl Neurobiol 2013;39:485-497.

65 Thal DR, Ghebremedhin E, Orantes M, Wiestler OD: Vascular pathology in Alzheimer disease: correlation of cerebral amyloid angiopathy and arteriosclerosis/lipohyalinosis with cognitive decline. J Neuropathol Exp Neurol 2003;62:1287-1301.

-66 Beach TG, Wilson JR, Sue LI, Newell A, Poston M, Cisneros R, Pandya Y, Esh C, Connor DJ, Sabbagh M, Walker DG, Roher AE: Circle of Willis atherosclerosis: association with Alzheimer's disease, neuritic plaques and neurofibrillary tangles. Acta Neuropathol 2007;113:13-21.

67 Honig LS, Kukull W, Mayeux R: Atherosclerosis and AD: analysis of data from the US National Alzheimer's Coordinating Center. Neurology 2005;64:494-500.

68 Roher AE, Esh C, Rahman A, Kokjohn TA, Beach TG: Atherosclerosis of cerebral arteries in Alzheimer disease. Stroke 2004;35:2623-2627.

69 Zekry D, Duyckaerts C, Moulias R, Belmin J, Geoffre C, Herrmann F, Hauw JJ: Degenerative and vascular lesions of the brain have synergistic effects in dementia of the elderly. Acta Neuropathol 2002;103:481-487.

70 Aho L, Jolkkonen J, Alafuzoff I: Beta-amyloid aggregation in human brains with cerebrovascular lesions. Stroke 2006;37:2940-2945. 
71 Luoto TM, Haikonen S, Haapasalo H, Goebeler S, Huhtala H, Erkinjuntti T, Karhunen PJ: Large vessel cerebral atherosclerosis is not in direct association with neuropathological lesions of Alzheimer's disease. Eur Neurol 2009;62:93-98.

72 Tomimoto H, Akiguchi I, Suenaga T, Nishimura M, Wakita H, Nakamura S, Kimura J: Alterations of the bloodbrain barrier and glial cells in white-matter lesions in cerebrovascular and Alzheimer's disease patients. Stroke 1996;27:2069-2074.

-73 Haller S, Kövari E, Herrmann FR, Cuvinciuc V, Tomm AM, Zulian GB, Lovblad KO, Giannakopoulos P, Bouras C: Do brain T2/FLAIR white matter hyperintensities correspond to myelin loss in normal aging? A radiologicneuropathologic correlation study. Acta Neuropathol Commun 2013;1:14.

74 Simpson JE, Ince PG, Higham CE, Gelsthorpe CH, Fernando MS, Matthews F, Forster G, O’Brien JT, Barber R, Kalaria RN, Brayne C, Shaw PJ, Stoeber K, Williams GH, Lewis CE, Wharton SB; MRC Cognitive Function and Ageing Neuropathology Study Group: Microglial activation in white matter lesions and nonlesional white matter of ageing brains. Neuropathol Appl Neurobiol 2007;33:670-683.

-75 O’Sullivan M, Summers PE, Jones DK, Jarosz JM, Williams SC, Markus HS: Normal-appearing white matter in ischemic leukoaraiosis: a diffusion tensor MRI study. Neurology 2001;57:2307-2310.

76 Moody DM, Brown WR, Challa VR, Anderson RL: Periventricular venous collagenosis: association with leukoaraiosis. Radiology 1995;194:469-476.

-77 Moody DM, Brown WR, Challa VR, Ghazi-Birry HS, Reboussin DM: Cerebral microvascular alterations in aging, leukoaraiosis, and Alzheimer's disease. Ann NY Acad Sci 1997;826:103-116. 